\title{
The Use of the Instrumental and Interactive Approaches of Communicative Intervention in the Control of Foot and Mouth Disease in the Eastern Cape
}

\author{
Ogundiran Oluwasola Adekunle ${ }^{1}$ \\ ${ }^{1}$ Department of Agricultural Economic, Extension and Rural Development, University of Fort Hare, Alice, South \\ Africa \\ Correspondence: Ogundiran Oluwasola Adekunle, Department of Agricultural Economic, Extension and Rural \\ Development, University of Fort Hare, Alice, South Africa. Tel: 27-083-570-3601. E-mail: \\ ogundiranoluwasola@yahoo.com
}

Received: August 19, 2013

Accepted: September 13, 2013 Online Published: November 15, 2013

doi:10.5539/jas.v5n12p87

URL: http://dx.doi.org/10.5539/jas.v5n12p87

\begin{abstract}
The instrumental and interactive approaches of communicative intervention are indeed two models of communication for development with two different ideologies. Why the instrumental approach is a one-way, domineering, media-centric and persuasive in outlook, and perhaps that is why it is a major tool in the hands of most political actors; the interactive approach is a two-way, participatory and people-oriented in outlook. The study reveals that these approaches of communicative intervention are best suited for two different occasions. The use of these two approaches in the adoption process of the new innovation: STAGE 1, 2, 3 vaccines, for the control of foot and mouth disease in the Eastern Cape is indeed revealing. The instrumental model, as you would expect, was disposed to the use of coercing mechanisms such as policies, incentives and the mass media, the interactive mode was tilted along the line of participation and due consultation of the local people. However, the characters of these two intervention approaches explain better their ideologies. Therefore, to attain a development that will be both participatory in nature, and as well portray the goals of political players, the need for a compromise of the two models is suggested in the study.
\end{abstract}

Keyword: communication, foot and mouth disease, method and eastern cape

\section{Introduction}

One of the basic functions of communication as revealed in the study of agricultural extension is that of persuasion. Persuasion here speaks of being able to convince people. Albert Einstein is quoted by Jacobson (1983: 31) to have said: "it is harder to understand the behavior of human beings than to understand that of atoms". This in itself presupposes the complexities and dynamics associated with human behavior. The complexities become worse when we start talking of the rural people. This is why various governments, in their quest to influence the behaviors of their rural people, towards the adoption of new technological innovations, especially on issues of agriculture, looks for communicative approaches of optimum effect. In the Eastern Cape, one ailing an agricultural problem that has been of great concern to the Provincial Government is that of "foot and mouth" disease. According to the World Assembly of Delegates of the OIE report of May, 2009, foot and mouth disease is one of the most contagious animal diseases. And in fact, it is acclaimed as the most contagious disease of mammals and has a great potential for causing severe economic loss in susceptible cloven-hoofed animals. A lot of control measures have been adopted over the years with varying degrees of success. But after a long search, the government, through its agricultural research center, has discovered a lasting solution to this long-standing problem. It is called the "S-1, 2, 3 -V" (stage-1, 2, 3-vaccine) measure. Because of the efficacy of this new measure/innovation, the government of the region has therefore, through its agricultural extension department, decided on two communicative intervention approaches to convince her farmers/rural people of accepting and adopting this innovation. These approaches are the instrumental and interactive approaches of communicative intervention.

Therefore this study is an analysis of how these approaches are utilized in the intervention process. It therefore begins with an explicit introduction, which is rather a fore-taste of the entire work, and then a definition of some basic terms introduced by the study, such as: the Eastern Cape provincial government; foot and mouth disease; 
innovation and adoption. A detailed description of instrumental and interactive methods of communicative intervention is what follows next, and then an X-ray of the workability of the new-found innovation for the control of foot and mouth disease. Thereafter the practical usage of the two approaches as applied to the Eastern Cape farmers is outlined. Furthermore a comparative view of the two approaches and their shortcomings are also brought to bear. While conclusion, recommendation and references forms the last section of the work.

\section{Definition of Terms}

For a proper understanding of this study, there is a need to define and explain some basic terminologies introduced in the study. These are:

\subsection{The Eastern Cape Province}

The Eastern Cape is a province of South Africa. Its capital is Bhisho. It was formed in 1994 out of the "independent" homelands of Transkei and Ciskei, as well as the eastern portion of the Cape Province. Landing place and home of the 1820 settlers, it is partly the traditional home of the Xhosa, and the birthplace of many prominent South Africans, such as Nelson Mandela, Thabo Mbeki, Steve Biko, and Charles Loghlan. (Wikipedia: the free encyclopedia). The Eastern Cape has a head of government and premier of the region called Premier Noxolo Kiviet.

\subsection{Foot and Mouth Disease}

Another term introduced by the study is "foot and mouth disease". Foot and mouth disease is a viral disease of the family picornaviridae, genus Aphthovirus. There are seven serotypes of the disease, which includes O, A, C, SAT 1 , SAT 2, SAT 3, and ASIA 1. One peculiar thing about the disease is that infection with one serotype does not confer immunity against another. The disease usually affects animals such as Bovidae (cattle, zebus, domestic buffalos, and yaks), sheep, goats, swine and all wild ruminants, and Suidae. The virus can persist in contaminated fodder and the environment for up to one month, depending on the temperature and $\mathrm{PH}$ conditions. The disease is noticed as lesions/ blisters on the tongue, gums, hoof deformation, etc. There is low mortality rate in adult animals but high mortality in young due to myocarditis.

\subsection{Innovation and Adoption}

A third basic term to consider as introduced by this study is innovation and adoption. According to Bembridge (1991: 269), innovation is defined as something regarded as new in a given locality or by a group of people. This definition reveals the fact that innovation as a word is relative/ subjective. In other words, something regarded as new in area A may already have been known in area B. On the other hand, adoption is defined as the act of accepting an innovation (new idea, practice or tool) (Bembridge, 1991).

\section{The Interactive and Instrumental Models of Communication}

The instrumental and interactive models of communication are two amongst various approaches used by different governments in the development process of their communities. In this section, these two methods are explained as found in the literatures.

\subsection{Instrumental Approaches}

During roughly the 1950 to 1990 period, it was quite common in development circles to think of change and innovation as something that could be planned. It was thought useful to define in advance clear goals and outcomes for the future (in connection with the problem of that moment), and possibly to organize rationally a series of steps that would eventually lead to the desired outcomes (Leeuwis \& Van den Ban, 2004). In accord with the above views, instrumental approach of communication is likened with such terms as "Top-down", "blueprint" planning, and "mechanical" process, as the case may be. From these ideas, human behavior and change is seen as highly predictive. Also, taking a cursory look further at the concepts as presented above, certain truths will be unveiled. Firstly, Top-down speaks of a management situation, where orders are issued from above (high-ranked officers) and the junior staff is not given any room to respond/feedback. Again, blueprint planning sees human behavior as a form of table-top process, where change is seen as a step one, two, three and so forth thing.

In other words, a plan of action is drawn by experts and taking to the field for implementation. Another word to be considered as used by the above authors is mechanical process, wherein behavior is seen as a machine that has no word of its own, which is only driven by an operator. But the question is, is human behavior and change truly a one-way process as seen from the above? The answer is certainly no. In their opinions, Leeuwis and Van de ban (2004) went on to say that instrumental approach of communication is characterized by two main interrelated features. First is that, it does take place after the goals of an endeavor and the corresponding policies and/ or innovation have been defined by concerned agencies. A second feature is that communication is used deliberately 
as a policy instrument (in conjunction with other instruments) in order to steer and direct human behavior, which is thought of as being largely predictable. Along these thoughts also, Richards, Thomas, and Nain (2001) stated that instrumental approach is referred to as diffusion/mechanistic approach. "According to Everett Rogers (1986) one of the leading proponents of diffusion theory, this perspective implies the role of communication was 1) to transfer technological innovations from development agencies to their clients, and 2) to create an appetite for change through raising a 'climate for modernization among the members of the public (p. 49). The elitist, vertical, or top-down orientation of the diffusion model is obvious" (Richards et al., 2001). The above statements agree with Leeuwis and Van de Ban's idea of referring to instrumental model as top-down, blue-print planning and the likes. In other words, it is something done by experts to lay people. In sum, we could characterize this communication perspective as "sender - and media - centric". In conjunction with the discussion with the mass media, it led to a conceptualization of communication as something one does to another (Richards, Thomas, \& Nain, 2001). As seen from the above, examples of this kind of approach could be development plans, such as national development plans, or on the global scale, millennium development plans; government policies; any of the communication media, like the mass media and the print media; etc.

\subsection{Interactive Approach of Communicative Intervention}

Interactive is from a root word "interact", which means to talk to each other and affect each other (Longman, 2003). From this definition, when people interact, they share things in common; there is understanding and a high level of feedback; there is no senior or junior; and it's usually a two-way process of communication. This is why Leeuwis and Van de Ban (2004) described the model as a participatory form of communication, because every party contributes to the process. In fact, Van Woerkum et al. (1999) opined that, the role of communication is not so much as to "sell" or "implement" pre-defined goals, policies and innovations, but rather to help generate and design appropriate goals, policies, and innovations in close interaction with societal stakeholders. One very close term to interactive communication is participatory communication. The study of participatory communication emerged in the late 1970s and took prominence in the 1980s; in part, it emerged as a counterbalance to theories such cultural imperialism. While cultural imperialism focused on the ability of the powerful to influence cultures and economics around the world, advocates for participatory communication sought to describe the power of the individual to influence the world and to find ways to further advocate and enrich such action with the ultimate goal residing in a utopian scenario of positive development for all and better inter-cultural understanding. Dervin and Huesca (1997) in their meta-analysis, stated that participatory communication is understood as being at the heart of what it means to be human to have an identify, and to possess a sense of belonging vis-à-vis humanity, nature and "God". They view participation as being central to positive or successful development. Participatory whim thrives on input from people from all works of life and of every socioeconomic sphere. It stresses the basic right of all people to be heard, to speak for themselves and not be represented or recorded by another party (Mcphail, 2009). Also participatory communication relies on the horizontally constructed exchange of information rather than the traditional, vertical dissemination of knowledge from the top down.

Again in the words or Richards, Thomas, and Nain (2001) interactive communication is referred more as participatory communication. In their words, participatory model stresses the importance of cultural identity of local communities and of democratization and participation of all level - international, national, local and individual. Paulo Freire (1983) refers to this as the right of all people to individually and collectively speak their word: "This is not the privilege of some few men, but the right to every man. Consequently, no one can say a true word alone, nor can one say it for another, in a prescriptive act which robs others of their words". Participatory research is an alternative social research approach in the context of development. It is alternative, because although business, government and the academic also undertake research with development in the end view, little thought and effort go as to how the research project can be used for the benefit of those researched. The central element of participatory research is participation. It is an active process whereby the expected beneficiaries of research are the main actors in the entire research process, with the researcher playing a facilitator's role (Philippine partnership for the Development of Human Resources in Rural Areas, 1988).

\section{The New-Found Innovation for the Control of Foot and Mouth Disease in the Eastern Cape}

Because of the economic damage of foot and mouth disease in the Province of the Eastern Cape, the government of the area had directed its agricultural research centre to look for a lasting solution to the ugly menace caused by the disease. As such, after some careful search, a new and more reliable drug was discovered. This is a vaccine called the STAGE 1, 2, 3 vaccine (S-1, 2, 3-V). The STAGE 1, 2, 3 vaccine has been acclaimed the best ever discovered measure for the control of foot and mouth disease. This is for two reasons. One of it is that the drug combines the benefits of all other drugs/measures ever used for the control of the disease. Secondly is that, the vaccine performs a double-barrel function. It performs a preventive function and also a curative function. 
The vaccine administration is spread over a period of three consecutive months. This is why it is called STAGE 1, 2, 3. In the first month, a $250 \mathrm{ml}$ of the drug is given to the animal in question. In the second month, the exercise is repeated again. This time, it is rather a $500 \mathrm{ml}$, while a $1000 \mathrm{ml}$ is administered in the third month. The animal is then left for another two extra months. Within this entire period, any available virus of the disease in the animal body is totally eradicated, while the animal's immune system is also beefed up so that the disease cannot be able to infect the animal anymore.

\section{The Practical Usage of Instrumental and Interactive Means of Communication in the Control of Foot and Mouth Disease in the Eastern Cape}

As so far discovered in this study, instrumental and interactive approaches are two forms of communication in development communication or communicative intervention processes. But based on decision (by policy makers), either or both approaches could be utilized together..." (Leeuwis \& Van de Ban, 2004). In this section, a practical usage of the two approaches in the control of foot and mouth disease in the Eastern Cape are demonstrated

\subsection{Using the Instrumental Approach}

Our study has revealed so many things about the instrumental approach. One of such is that instrumental approach is a "top-down" approach (Leeuwis \& Van de Ban, 2004), like in an organizational relationship, where a boss give orders and no room is given for feedback, and a "sender- and media centric" form of communication (Richards, Thomas \& Nain, 2001). This implies a one-way approach. Another thing is that it is derived from a worldview of dominance, persuasion and akin to the modernization/diffusion philosophy. This sees development communication in the light of how modernization in Europe spread to other areas in the 17th century. Using this approach to persuade farmers to adopt the STAGE 1, 2, 3 vaccines in the control foot and mouth disease in the Eastern Cape will take the following processes, which is divided into three parts.

\subsubsection{The Use of Policies and Incentives}

The Department of Agriculture in the Eastern Cape, being the governing body of agriculture in the area, will have to issue a new policy or law with respect to the new approach for the control of foot and mouth disease. Haven been informed by its agricultural research centre about the efficacy of the new innovation: STAGE 1, 2, 3 vaccines, the government will have to issue a new policy to enforce its usage. And perhaps add some other incentives such as making the vaccine and the services of veterinary doctors, who will administer them, free for all her farmers/subjects.

\subsubsection{The Role of the Mass Media}

Having drawn its policy, the government also will have to ensure the use of appropriate mass media to relay its new policy to all its farmers. This could be through the use of any of the available mass media, e.g. SABC T.V and Radio, and any of the newsletters, etc. The goal of this is to try and influence the minds of its farmers to adopt this new innovation.

\subsubsection{Extension Agents}

Another means that could be used in communicating its policy to the farmers is via the extension agents. The work of these people is basically to inform the communities about the innovation and why they need to adopt it.

\subsection{Using the Interactive Approach}

This study reveal that interactive communication, unlike instrumental approached, is a two-way process, and it is likened to participatory form of communication (Leewis \& Van de Ban, 2004). This is a communication that is not aimed at dominating and coercing others, but every party contributes in the process. Using this approach in the persuasion of farmers in the Eastern in the adoption process of STAGE 1, 2, 3 vaccines, will take the following process. Due to the structure of the drug: STAGE-1, 2, 3-vaccines, the process is spread into specific periods of administration for optimum success.

\subsubsection{The First Visit}

The extension officer will first have to visit the community and invite all the farmers for a meeting. The aim of this meeting is to:

a. Introduce the new technology: STAGE 1, 2, 3 vaccines.

b. Know from the farmers the method they have been using in controlling the disease.

c. Know from the farmers and record the level of results they have been getting.

d. Explain all that the farmers stand to gain if they adopt the innovation. 
e. Arrange with the farmers for a demonstration farm exercise; to demonstrate the new innovation.

f. Set up dates to begin the exercise.

g. Agree for dates of meetings, for observations.

h. Elect representative farmers to oversee the demo farms.

\subsubsection{The Second Visit}

On the second date of visit, the different demonstration farms are established. One of the farms (farm A) is to be overseen by the extension agent. On this farm, animals are put in the farm to demonstrate the efficacy of the vaccine. A second farm (farm B) is also to be established, which is to be overseen by the farmers. On this the old method is to be demonstrated as well, while a third farm (farm C) was to be a control farm. In farm A, healthy marked animals are mixed up with foot and mouth disease infected animals, and well fed for about two weeks. Also in farm B, healthy marked animals are mixed with foot and mouth disease infected animals and well fed also for two weeks. While in farm C, healthy marked animals are mixed with foot and mouth disease infected animals and well fed for about two weeks as well. At the end of two weeks, STAGE 1, 2, 3 vaccines was administered to all the animals in farm A. This is repeated for three consecutive months and then observed for about two months. Likewise the old method which the farmers in the Eastern Cape have been using to control foot and mouth disease was also administered to all animals in farm B and also observed for the same period. The control farm C was left without any form of control measure and observed for the same period.

More so, at the end of the entire period, which is about six months, observations was made and comparisons done. It was found that while the healthy marked animals in farm A had no trait of the disease, B and C both had some of their animals infected and even some deaths (of the young ones) also recorded, although the level of disease infection was higher in $\mathrm{C}$ than $\mathrm{B}$. Another remarkable observation was that, because of the vaccine administered to the unhealthy animals in farm A, the animals were totally cured of their disease at the end of the entire period. This means that one importance of the STAGE 1, 2, 3 vaccines is that, it has both a preventive and curative value. In the same vein, unhealthy animals in B had some cure, but the rate of success was so slow to be of any economic importance, while those in farm $\mathrm{C}$ had no change at all.

\subsubsection{The Final Meeting}

Please note that in between the second and final meeting, there are so many other meetings that are not recorded.

The observation was done by all. From a general consensus, the whole farmers in the community were all convinced without any doubt that the STAGE 1, 2, 3 vaccine (new innovation) was to be preferred to any other methods they had before. Therefore, there was a wide range of acceptance and adoption. In fact, many of the farmers even pledged to help in the spread of the innovation.

\section{Comparisons and Shortcomings of the Instrumental and Interactive Models of Communicative Intervention}

From the ideas of Richards, Thomas and Nain (2001), the characteristics of the instrumental and interactive approaches of communication are compared in this section of study. Firstly, interactive/participatory research rests on the assumption that human beings have an innate ability to create knowledge. On the hand, knowledge production is considered as monopoly of "professionals" by the instrumental/diffusion model. Secondly, the instrumental approach sees the researcher as a "social engineer"; one who does development for the people. But the participatory approach sees the researcher only as a facilitator; one whose duty is to assist the researched solves their own problem. Thirdly, the instrumental model sees development as a process of monologue, but the participatory and interactive model sees development as a dialectical process of dialogue between the researcher and the community.

Fourthly, the participatory model sees people as the controlling actors or participants for development. As such, they own their development. The instrumental approached where people are alienated from their own developmental process. Fifthly, under the instrumental approach, the process of development is a one-way process, unlike the participatory model where development is a two-way process. Sixthly, under the instrumental approach, the goals and plan of action is set by experts and professionals, while the goals and plan of action under the interactive model is the collective effort of the community. Again the instrumental approach emphasizes the will of the government or nation, unlike the interactive which focuses on the will of the local community. Moreover, mass media play the preeminent role in the campaign of development through the instrumental approach, but the will of the people play a major role in the case of interactive approach. Finally, the instrumental approach is derived from a world view of dominance over one's environment, and it is congruent with the western conception, where 
communication is overwhelmingly oriented to persuasion. But on the other hand, the interactive system of communication is derived from a participatory worldview.

\subsection{Shortcomings of the Instrumental and Interactive Approaches of Communication}

\subsubsection{Shortcomings of Instrumental Approach}

From experience, a great many changes and innovations that were planned never materialized, and original projects or policy goals were hardly ever realized. Moreover, intervention efforts often appeared to have unintended and unanticipated social and agro-ecological consequences. Hence, human behavior and society proved to be far less predictable and controllable than expected. Although on paper (e.g. in project documents and evaluation reports), projects looked straightforward and rationally organized, the everyday practice of projects was much more chaotic. One problem is that the people usually cannot lay any claim to development. There is also the problem of massive support by the people, because people usually support what they were part of building. There is again the problem of maintenance by the people, because the people were alienated from the planning process.

\subsubsection{Shortcomings of the Interactive Model}

1) Interactive processes can be very time consuming and costly for both communication workers and clients;

2) May generate little enthusiasm on the side of those who are supposed to participate;

3) Are frequently affected negatively by conflict, unequal power relations and /or unequal capacities to participate;

4) At times do not help to generate tangible results or innovations;

5) May end in compromises that nobody is really happy with;

6) Regularly produces outcomes that are ignored by those who are supposed to incorporate them;

7) Frequently raise high expectation which cannot be met;

8) May reinforce the position of relatively powerful and well- to- do clients;

9) often by-pass regular democratic procedures;

10) May prevent people from taking responsibility.

\section{Conclusion}

This study revealed that the instrumental and interactive approaches of communicative intervention are two methods of communication having two different ideologies. While the instrumental approach is from a worldview of dominance and is persuasive in nature, the interactive approach is participatory in nature. In the instrumental model, the goal of development is set before action and development is planned and imported into the community, while every member of the community is a contributor to both plan and implementation of development under the interactive mode. More so the professionals are the main actors in development under the instrumental model, the local people are the main actors under the interactive mode, while the researcher only plays a facilitating/assisting role under the interactive. The study also demonstrated how these two communicative ideologies were utilized in the adoption processes of a new-found innovation (STAGE 1, 2, 3 vaccines) for the control of foot and mouth disease in the Eastern Cape. Under the use of the instrumental model, the government of the province only from their office set in place the goal of communication, not minding whether the farmers had better reasons to have continued-on with their former control measure of the disease.

In the pursuance of their goal, the government also creamed up their plans with some coercive measures such as the use of binding policies on the farmers, incentives and the massive use of the mass media. In all of this, the will and participation of the local people were totally omitted. But with the use of the interactive model, although the innovation was created by the government, the will and participation of the local farmers were adequately consulted. This was to ensure that the adoption of the innovation was done out of their own will and volition and not something imposed on them. From the foregoing, it is understood that the instrumental and interactive methods of communicative intervention are two ideologies at two ends of a continuum. But the understanding of the intricacies of the two ideas is imperative for proper development. As our study revealed, the two ideologies could be best suited to two different occasions. For example, in a community that is too tied to cultural values that is anti change and development, the instrumental model could be best suited. But in a more globalized and democratized world like in our day, the interactive model would be a best fit. Also from the viewpoint of political actors, the instrumental approach is to be chosen, especially when development is for political reasons. However, for a development that will meet today's need, and that will merge the desires of the people with the goals of political actors, there is a need for a compromise of the good qualities of both approaches even as unveiled in this study. 


\section{References}

Bembridge, T. J. (1991). The Practice of Agricultural Extension: A Training Manual. DBSA: Halfway House.

Dervin, B., \& Huesca, R. (1997). Reaching for the Communicating in Participatory Communication: a Metatheoretical Analysis. Journal of International Communication, 4(2), 46.

Jacobsen, C. (1983). Human Behavior: Motives and Needs. In J. Chanoch (Ed.), Principles and Methods of Extension Work. Israel: The Israel Association for International Cooperation.

Leeuwis, C., \& Van den Ban, A. (2004). Communication for Rural Innovation: Rethinking Agricultural Extension (3rd ed.). UK: Blackwell Publishing Company.

Longman. (2003). Longman Dictionary of Contemporary English: The Living Dictionary (4th ed.). Oxford: Oxford University Press.

Mcphail, T. L. (2009). Development Communication: Reframing the Role of the Media. Blackwell Publishing, Ltd.

Philippine Partnership for the Development of Human Resources in Rural Areas. (1988). Retrieved 28th June, 2011,

from http://en.wikipilipinas.org/index.php?title=Philippine_Partnership_for_the_Development_of_Human_Reso urces_in_Rural_Areas

Richards, M., Thomas, P. N., \& Nain, Z. (2001). Communication and Development: The Foreign Connection. USA: Hampton Press Inc.

Rogers, E. (1986). Diffusion of Innovation. New York: The Free Press.

Van Woerkum, C. (1999). Interactive Policy-Making: The Principles. Wageningen: Wageningen Agricultural University.

Wikipedia: The Free Encyclopedia. Eastern Cape. (2011). Retrieved 27th July, 2011, from http://en.Wikipedia.org/wiki/EasternCape

World Assembly of Delegates of the OIE Report. (2009). Foot and Mouth Disease. Retrieved 27th July, 2011, from http://www.oie.int/downld/SG/2010/A_RESO_2010PUB.pdf

\section{Copyrights}

Copyright for this article is retained by the author(s), with first publication rights granted to the journal.

This is an open-access article distributed under the terms and conditions of the Creative Commons Attribution license (http://creativecommons.org/licenses/by/3.0/). 